\title{
IMPROVING DYNAMIC STABILITY OF POWER SYSTEMS BY USING AVR, POWER SYSTEM STABILIZER
}

\author{
Fuhaid Basheer \\ Faculty of Engineering, Tanta University, Tanta, Egypt. \\ Mohamed I. El-sayed \\ Faculty of Engineering (grails), Al-Azhar University, Cairo, Egypt. \\ El-Saied Othman \\ Faculty of Engineering, Al-Azhar University, Cairo, Egypt.
}

\begin{abstract}
This paper introduced a sum method for controlling electrical power systems for multi-machines under dynamic loads by using artificial intelligence.

This paper includes complete descriptions of the sum methods used to controlling dynamic power system stability through the method of recognizing pattern and proposition of suitable control systems for re-adjusting the machines in power system for instable cases. PSAT program had been used in analyzing the stability in the power systems. In this paper, the studied power system included dynamic load model, the program gave excellent results in standard time, and the used network consists of 9 bus bars - 4 generators.
\end{abstract}

Keywords: Transient and Dynamic Stability, Load Model, Event Definition, AVR, PSS, and TG Control, Case Study.

Cite this Article: Fuhaid Basheer, Mohamed I. El-sayed, El-Saied Othman, Improving Dynamic Stability of Power Systems by Using AVR, Power System Stabilizer, International Journal of Electrical Engineering \& Technology, 10(2), 2019, pp. 36-47.

http://iaeme.com/Home/issue/IJEET?Volume=10\&Issue=2

\section{INTRODUCTION}

The first electric power system was a dc system built by Edison in 1882. The subsequent power systems that were constructed in the late 19th century were all dc systems. However despite the initial popularity of dc systems by the turn of the 20th century ac systems started to outnumber them. The ac systems were thought to be superior as ac machines were cheaper than their dc counterparts and more importantly ac voltages are easily transformable from one level to other using transformers. The early stability problems of ac systems were experienced 
in 1920 when insufficient damping caused spontaneous oscillations or hunting. These problems were solved using generator damper winding and the use of turbine-type prime movers.

The term dynamic stability also appears in the literature as a class of rotor angle stability. However, it has been used to denote different phenomena by different authors. In the North American literature, it has been used mostly to denote small-disturbance stability in the presence of automatic controls (particularly, the generation excitation controls) as distinct from the classical "steady-state stability" with no generator controls [1].

Particular interests in this paper are transient stability and small signal stability. Transient stability assessment (TSA) becomes a major concern because a fault or loss of a large generator can lead to large electromechanical oscillations between generating units that may rise to loss synchronism [2].

With the deregulation of electricity markets, the utilities are allowed to participate outside their traditional stability borders to maximize their income, thus critical oscillatory modes appear after small disturbances. Oscillations limit the amount of power that can be transferred and may lead to power system breakup and outage. The oscillatory stability assessment (OSA) can be characterized in terms of mode parameters, e.g. Frequency and damping of oscillations. Independent system operator is the responsible of a secure real time system operation; it means that after the disturbances the power system must be able to surviving and moving into an acceptable steady-state condition that meet all established limits. For safe system operation, several dynamic stability cases need to be run in a very short period of time (10-20 second) using online data to initiate preventive control actions. Thus system operators need different computational tools for system stability assessment. These tools must be accurate and fast for application. The power system stability can be classified into two category show in Figure1 [3].

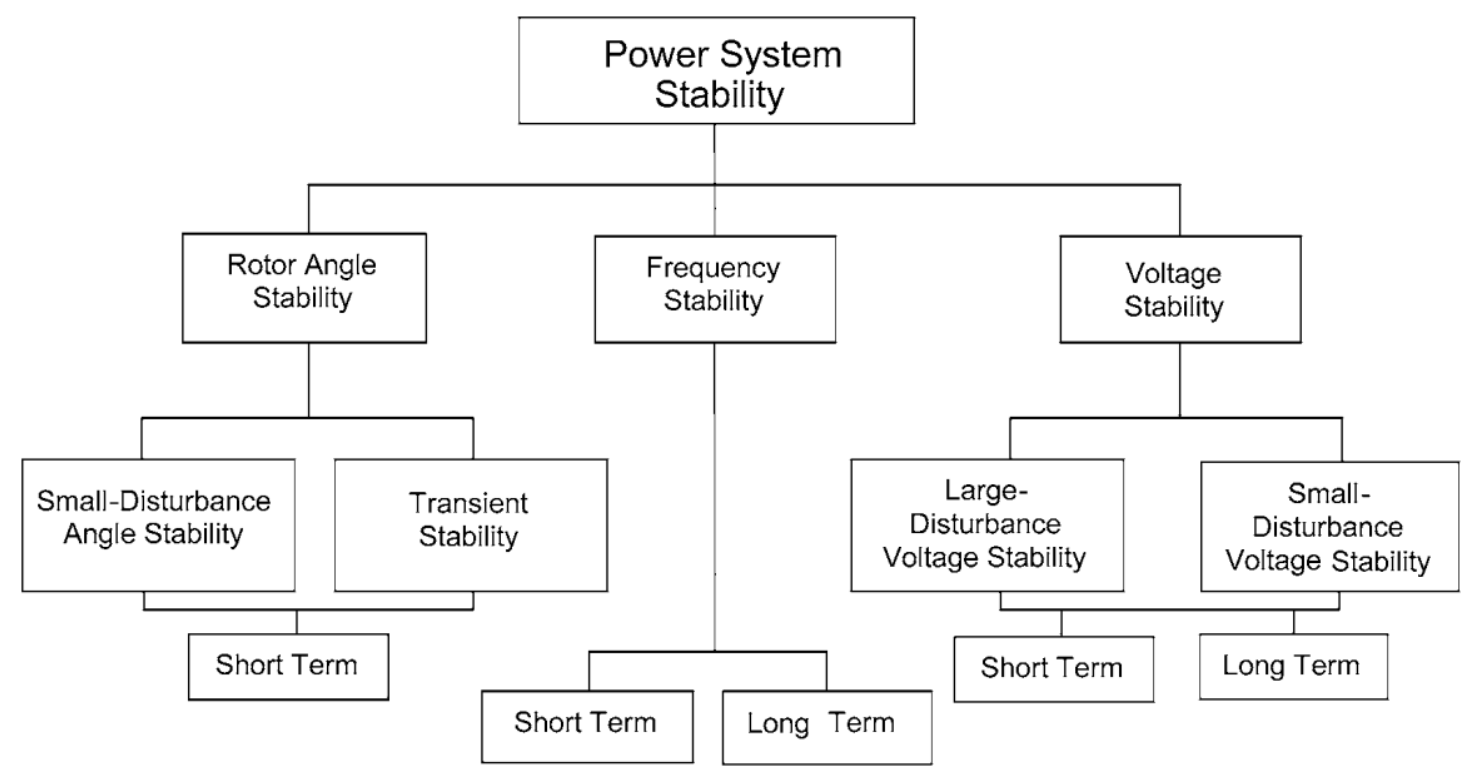

Figure 1. Classification of Power System Stability

\section{SMALL SIGNAL STABILITY.}

This paper describes improvement transient stability available in PSAT and the associated graphical user interface. After solving the power flow problem, it is possible to compute and visualize the eigenvalues and the participation factors of the system. The eigenvalues can be computed for the state matrix of the dynamic system $[4,5]$. 


\section{LOAD MODEL}

For improvement of dynamic stability under dynamic loads are required for dynamic motor starting, transient stability. Dynamic models and some control units (exciters and governors) are only needed for transient stability studies. In addition, load torque characteristics for different types of models are required for both motor starting and transient stability studies. PowerStation provides a variety of induction and synchronous machine models, plus extensive libraries for exciters and governors for you to select from to perform your studies.

For dynamic motor acceleration studies, only the motors that are accelerated need to have a dynamic model, i.e., generators, exciters, and governors are not dynamically modeled. For transient stability studies, all generators, exciters, and governors are dynamically modeled. Motors, which have dynamic models and are designated to be dynamically modeled from the study case, will be dynamically modeled. For generator starting and frequency dependent transient stability studies, all generators, exciters, governors, and motors have to use frequency dependent models.

The induction machine models section describes five different types of induction machine models and the frequency dependent forms of these models. Those are Circuit Models (Single1, Single2, DBL1, DBL2 and Characteristic Curve Models). Those are Equivalent Model, Transient Model for round-rotor machines, Sub-transient Model for round-rotor machines, and Transient Model for salient-pole machines, and Sub-transient Model for salient-pole machines. Motor starting and transient stability studies also require the utility tie system to be modeled as an equivalent machine. A description of the modeling of power grid systems is found in [6].

Different types of exciter and automatic voltage regulator (AVR) models, including standard IEEE models and vendor special models, are defined in the Exciter and AVR Models section. Governor-turbine models that are also based on both IEEE standards and vendors' product manuals are listed in the Governor-turbine Models section. Finally, different types of load models are described in the Mechanical Load section. [7].

\subsection{Dynamic Load Models}

When the traditional static load models are not sufficient to represent the behavior of the load, the alternative dynamic load models are necessary. The parameters of these load models can be determined either by using a measurement-based approach, by carrying field measurements and observing the load response as a result of alterations in the system, or by using a component-based approach; first by identifying individual load characteristics and then by aggregating them in one single load.

\subsection{Exponential Dynamic Load Model}

Due to the large amount of electrical heating loads in Sweden and its critical effect on voltage stability have proposed a load model with exponential recovery. The model is presented below, as a set of non-linear equations, where real (active) and reactive power have a nonlinear dependency on voltage $[8,9]$.

$$
\begin{gathered}
T_{p} \frac{d P_{r}}{d t}+P_{r}=P_{o}\left(\frac{U}{U_{o}}\right)^{\alpha_{s}}-P_{o}\left(\frac{U}{U_{o}}\right)^{\alpha_{t}} \\
P l=P_{r}+P_{o}\left(\frac{U}{U_{o}}\right)^{\alpha_{t}}
\end{gathered}
$$


Where Uo and Po are the voltage and power consumption before a voltage change, Pr is the active power recovery, $\mathrm{Pl}$ is the total active power response, $\mathrm{Tp}$ is the active load recovery time constant, $\alpha$ t is the transient active load-voltage dependence, and $\alpha$ s is the steady state active load voltage dependence. Similar equations are also valid for reactive power.

The load behavior is thus characterized by a time constant and transient and steady state load-voltage dependence parameters. Tp represents the time that the power recovery needs to reach $63 \%$ of its final value, $\alpha$ s the steady state load-voltage dependence quantifies how much load has been restored after the recovery; a value equal to 0 means a fully restored load, while a different value indicates partly restored load.

Furthermore, the parameter $\alpha$, steady state voltage dependency, may present negative values, the stationary level reached by the load after the recovery is then higher than the expected one, resulting in an overshooting in the load at the transient load-voltage dependence, describes how the load behaves at the disturbance moment. If $\alpha$ t is equal to 0 , the load behaves as a constant power, if it is equal to 1 the load behaves as a constant current, and if it is equal to 2 as constant impedance.[10,11,12].

\section{POWER SYSTEM CONTROL}

This paper describes regulators and some controllers used to control of power system dynamic stability. These are Turbine Governor (TG), Automatic Voltage Regulator (AVR), Power System Stabilizer (PSS) Control models are described by means of a set of differential equations, as follows [13]:

$$
\begin{gathered}
\mathrm{x}^{\cdot}=\mathrm{f}\left(\mathrm{x}, \mathrm{y}, \mathrm{z}_{\text {in }}\right) \\
\mathrm{z}_{\text {out }}=\mathrm{z}_{\text {out }}\left(\mathrm{x}, \mathrm{y}, \mathrm{z}_{\text {in }}\right)
\end{gathered}
$$

Where $\mathrm{x}$ are the state variable of the component, $\mathrm{y}$ the algebraic variables (e.g. bus voltages in case of AVRs), zin are the input variables (e.g. the rotor speed in case of TGs), and zout are the output variables (e.g. the synchronous machine field voltage and mechanical torque).

\subsection{Automatic Voltage Regulator}

Automatic Voltage Regulators (AVRs) define the primary voltage regulation of synchronous machines. Several AVR models have been proposed and realized in practice. PSAT allows defining three simple different types of AVRs. AVR Type I is a standard Italian regulator (ENEL), whereas AVR Type II is the standard IEEE model 1. AVR Type III is the simplest AVR model which can be used for rough stability evaluations [14].

\subsubsection{Automatic Voltage Regulator Type I}

The AVR Type I is defined by the block diagram shown in Figure 2.

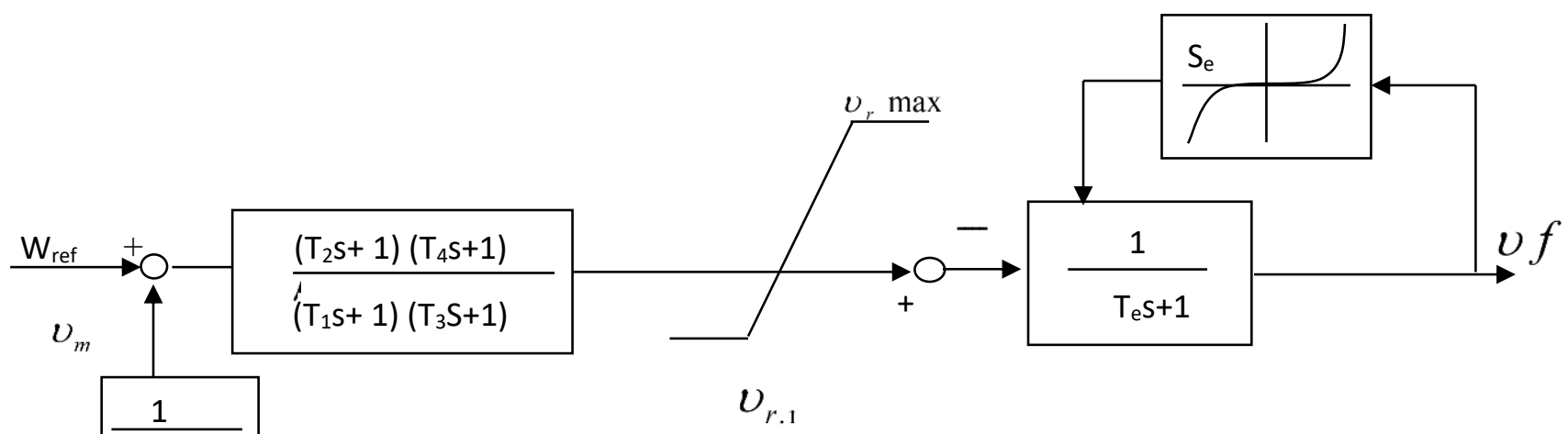

Figure 2. Exciter Type I. 


\subsection{Automatic Voltage Regulator Type II}

The AVR Type II is defined by the block diagram shown in Figure 3.

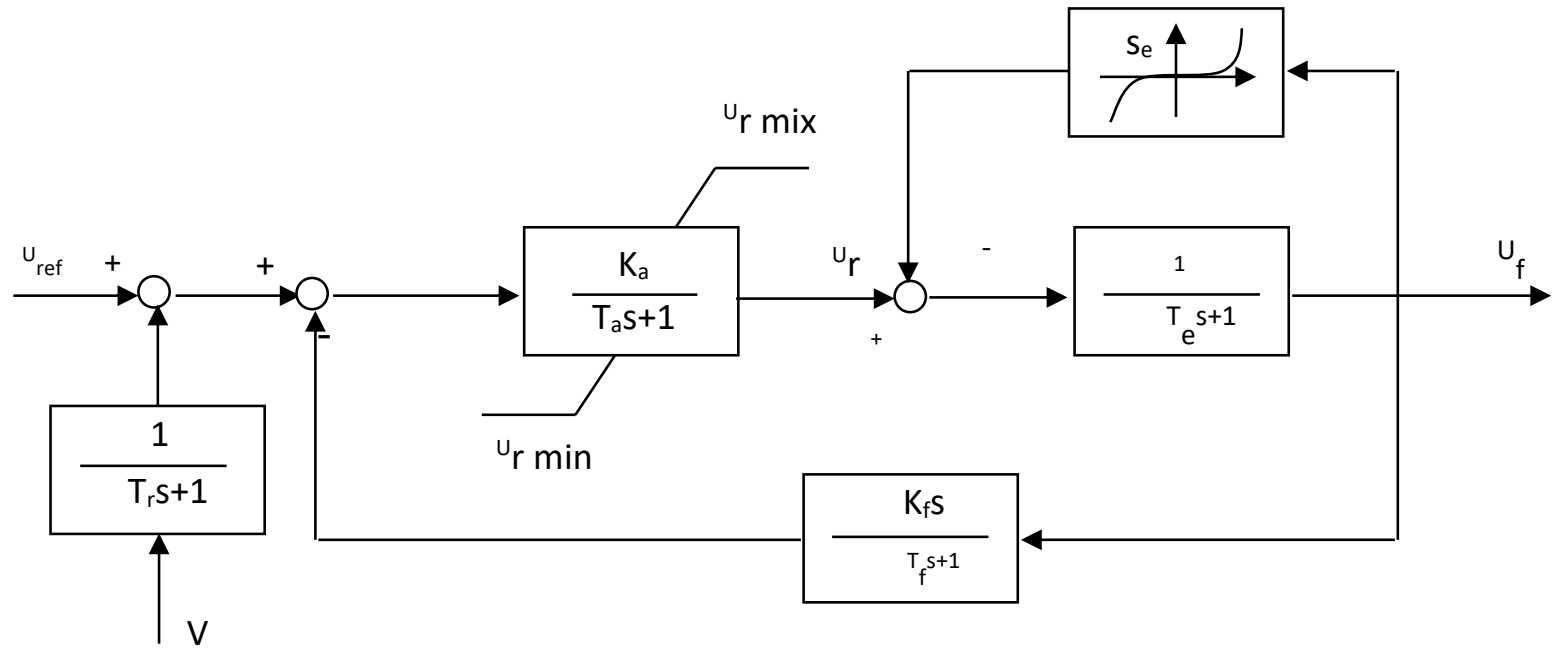

Figure 3. Exciter Type II.

\subsubsection{Automatic Voltage Regulator Type III}

The AVR Type III is defined by the block diagram shown in Figure 4.

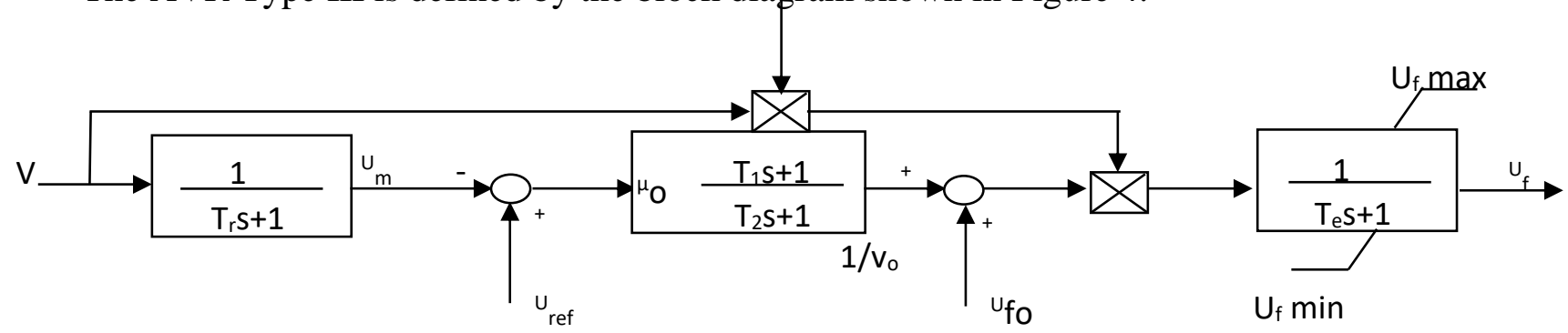

Figure 4. Exciter Type III.

\subsection{Power System Stabilizer}

Power System Stabilizers (PSSs) are typically used for damping power system oscillations and many different models have been proposed in the literature. In addition to the simple PSS embedded in the synchronous machine equations (models III, IV,V.1, V.2 and VI), five models of PSS are implemented in PSAT $[15,16]$.

All models accept as input signals the rotor speed $\omega$, the active power Pg and the bus voltage magnitude $\mathrm{Vg}$ of the generator to which the PSS is connected through the automatic voltage regulator. The PSS output signal is the state variable vs, which modifies the reference voltage vref of the AVR. The output signal vs is subjected to an anti-windup limiter and its dynamic is given by a small time constant $\mathrm{TC}=0.001 \mathrm{~s} .1$ Note that PSSs cannot be used with order II generators. Each PSS model has two algebraic equations, as follows:

$$
\begin{aligned}
& 0=\mathrm{g}_{\mathrm{s}}(\mathrm{x}, \mathrm{y})-v_{\mathrm{ss}} \\
& 0=v_{\text {ref } 0}-v_{\text {ref }}+v_{\mathrm{ss}}
\end{aligned}
$$

Where (5) defines the PSS signal uss, and (6) sums the signal vss to the AVR reference voltage. 


\subsubsection{Power System Stabilizer Type I}

PSS Type I is defined by the block diagram shown in Figure 5.

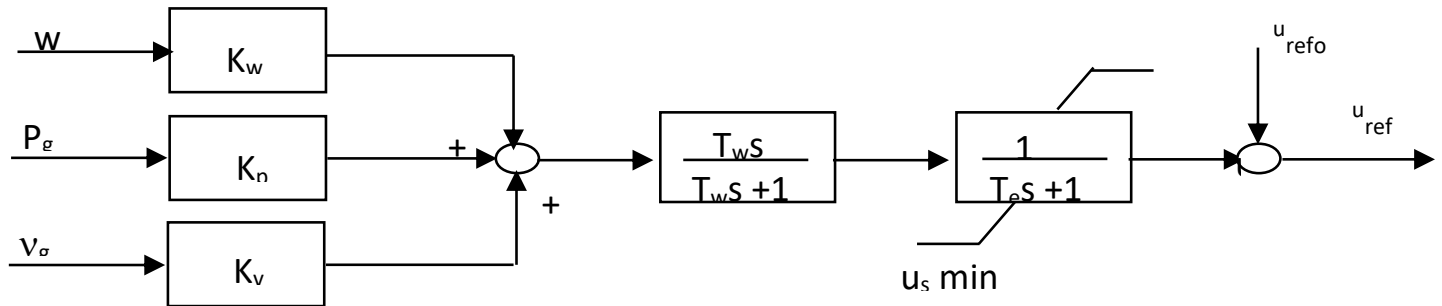

Figure 5 Power system stabilizer Type I.

\subsubsection{Power System Stabilizer Type II}

PSS Type II is defined by the block diagram shown in Figure 6.

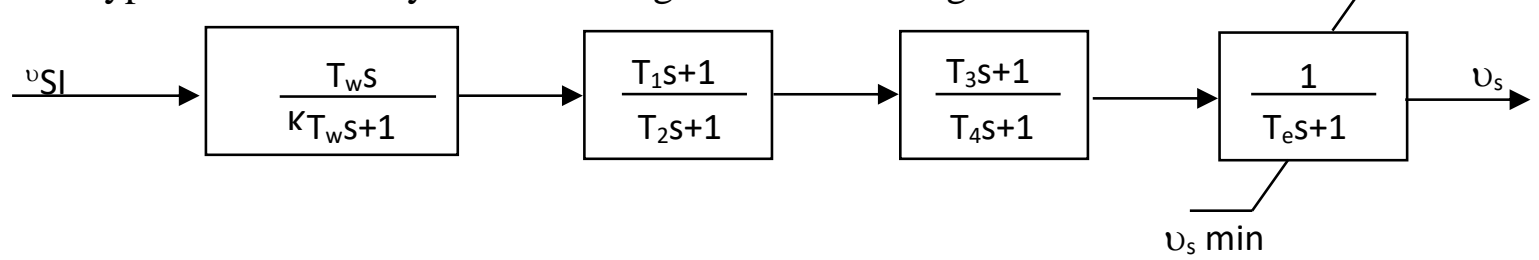

Figure 6 Power system stabilizer Type II.

\subsubsection{Power System Stabilizer Type III}

PSS Type III is defined by the block diagram shown in Figure 7.

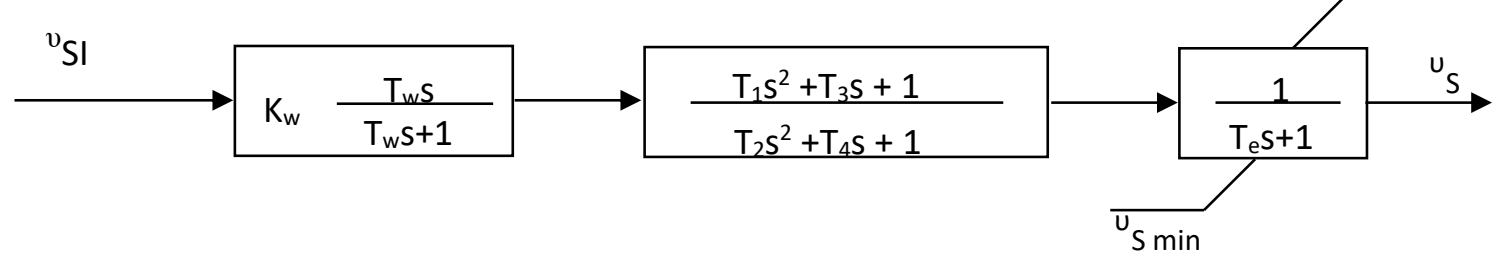

Figure 7. Power system stabilizer Type III.

\subsubsection{Power System Stabilizer Type IV and V}

PSS Type IV and V are a slight variation of Type II and III respectively. The block diagram is depicted in Figureure 9. The additional signal $v \alpha$ is generally disabled, being the switch S1 open. S1 closes if the machine field voltage is lower than a threshold value of $<$ ethr and remains closed even after of $\geq$ ethr. S1 opens if the rotor speed is lower than a threshold value $\omega<\omega$ thr.

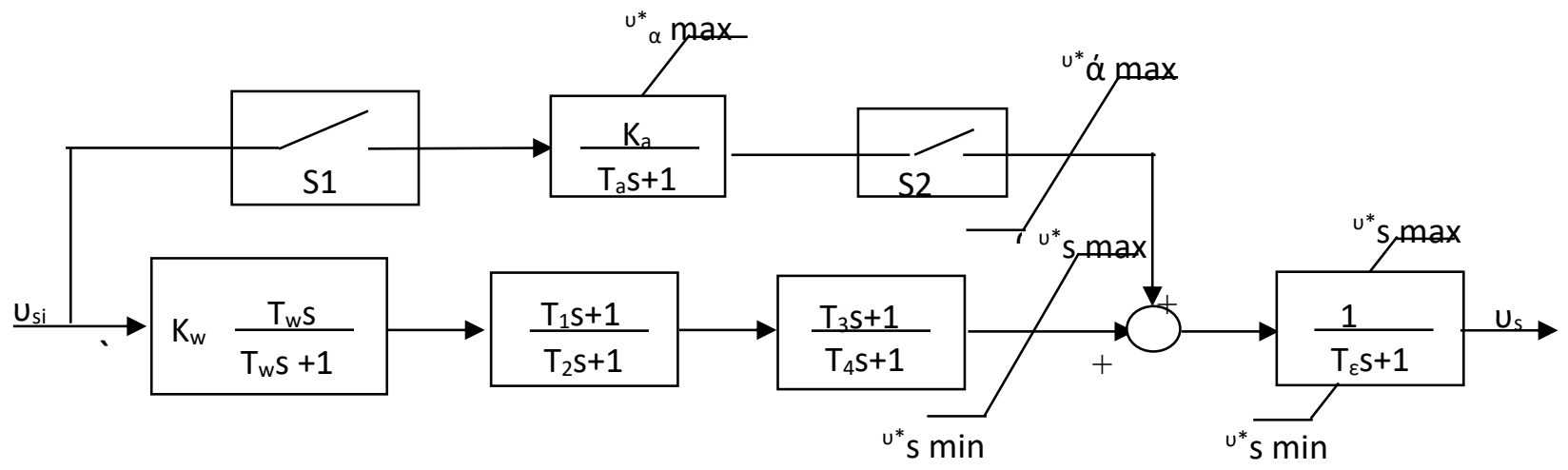

Figure 8. Power system stabilizer Type IV. 
It is possible to enable the action of a second switch S2 after the lag block of the additional signal $v \alpha$. If S2 is enabled, it stays generally open. S2 closes when the rotor speed deviation $\Delta \omega<0$ and remains closed even after $\Delta \omega \geq 0$

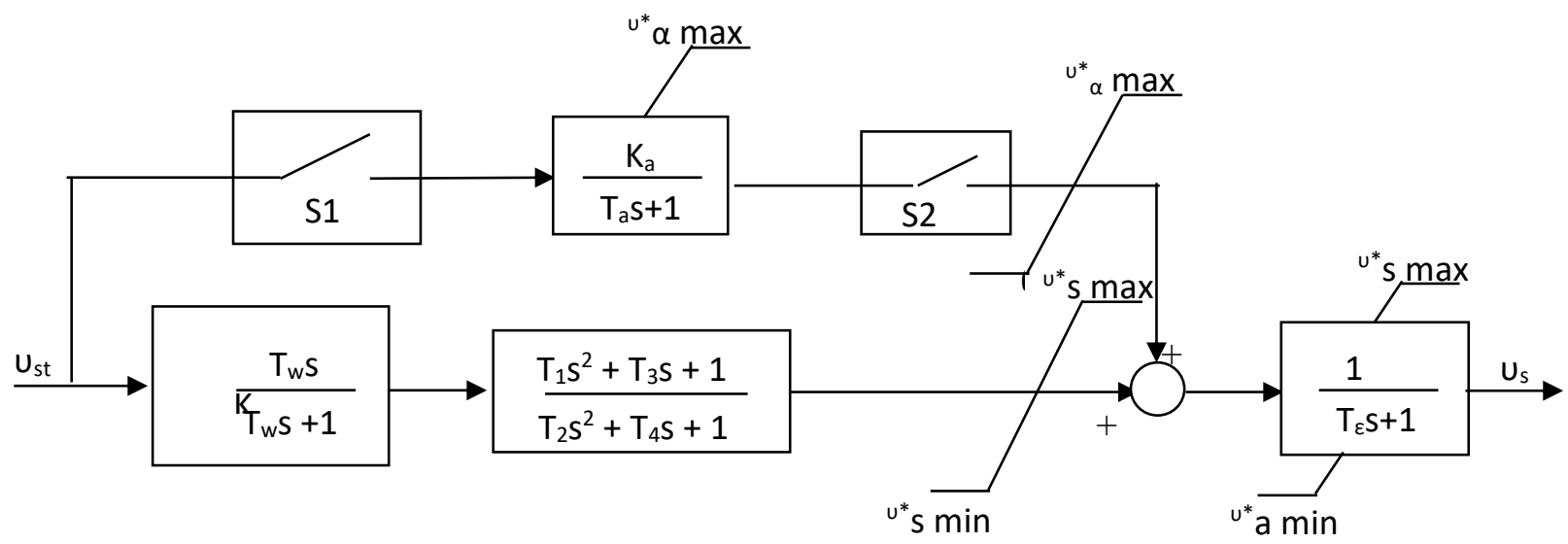

Figure 9 Power system stabilizer Type V

\section{CASE STUDY}

Test results are providing on the 9 Bus systems. Figure 10 show the single line diagram for network used in case study.

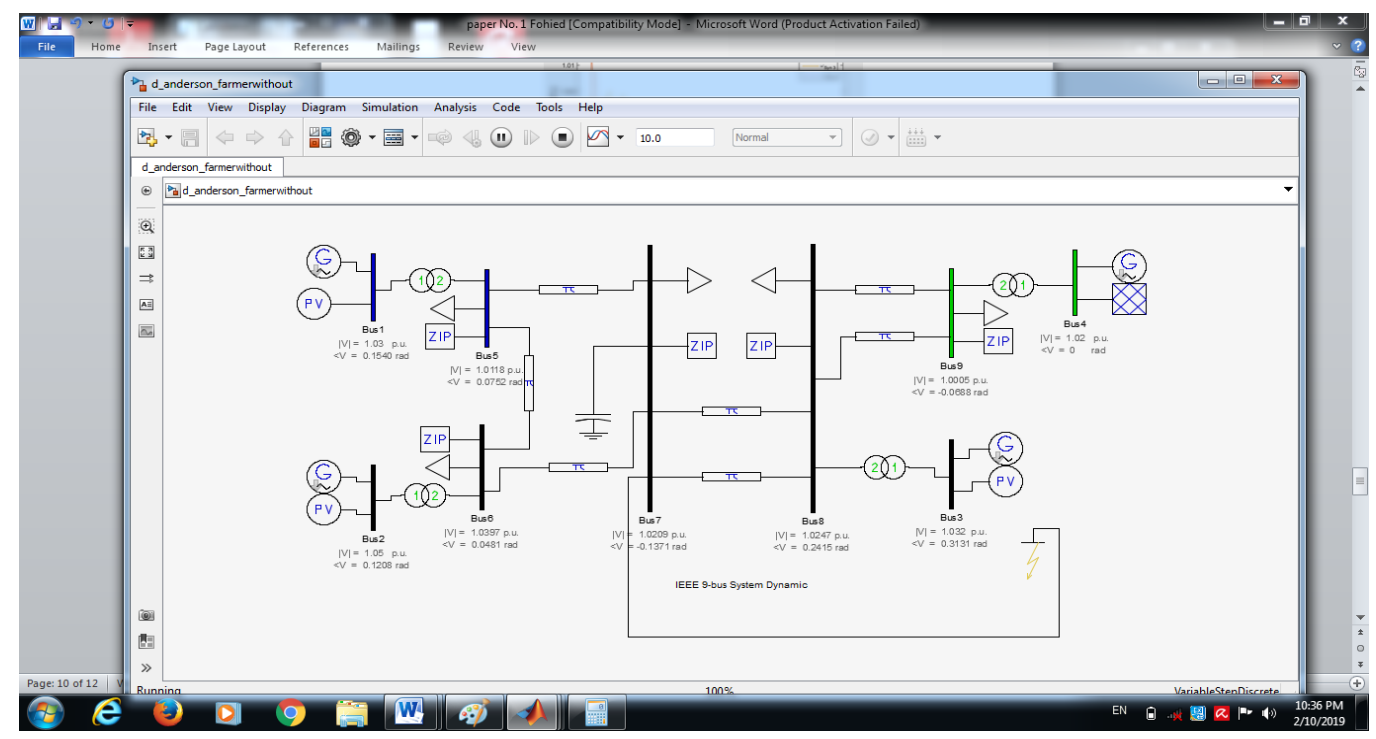

Figure 10. Show the single line diagram for 9 Bus Network

A two new event was considered and the PSAT program was used to analysis and evaluate the dynamic stability of the system and to propose the required a suitable preventive control action fore readjustment the network to steady state.

These two events were:

- A 3-phase short circuit at the bus 3

- A 3-phase short circuit at the bus 7

In the following cases, three phase short circuit made for bus No. 3 and 7, and the following curves for power angle against time and speed against time to all generators in cases of use the control and without control. 


\subsection{Case No. 1: A 3-phase short circuit at the bus No. 3}

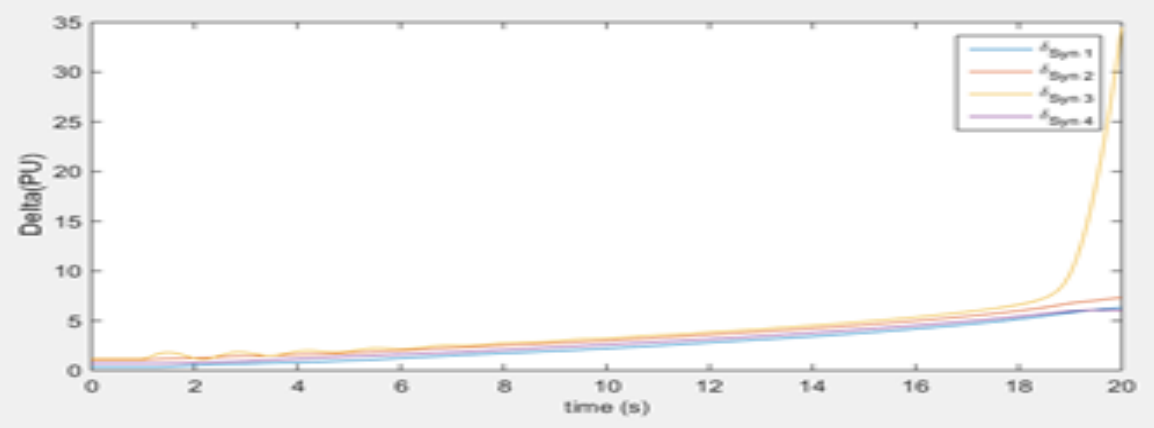

Figure 11 Represent Delta against Time for All Generators When the Fault Occurs at Bus No.3 without Control.

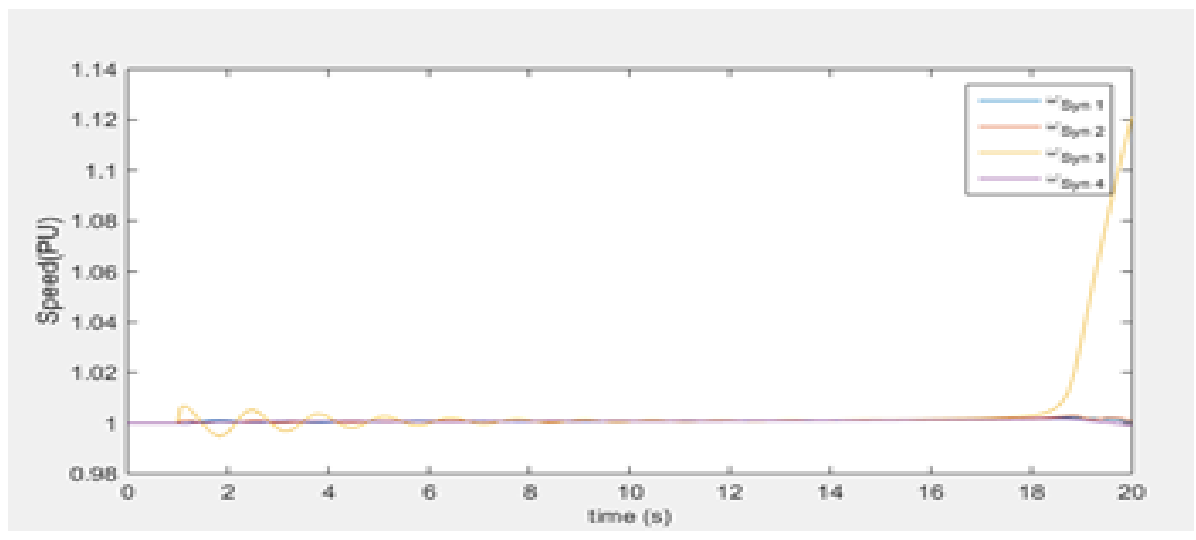

Figure 12 Represent Speed against Time for All Generators When the Fault Occurs At Bus No.3 Without Control

In this case, the fault that lasted for 0.066 seconds results instability for generator no. 3 in the network, AVR type 2 , TG type 2 and PSS type 2 were used for re-adjusting the generators and the following curves indicates Delta against time and speed against time after using of the control devices.

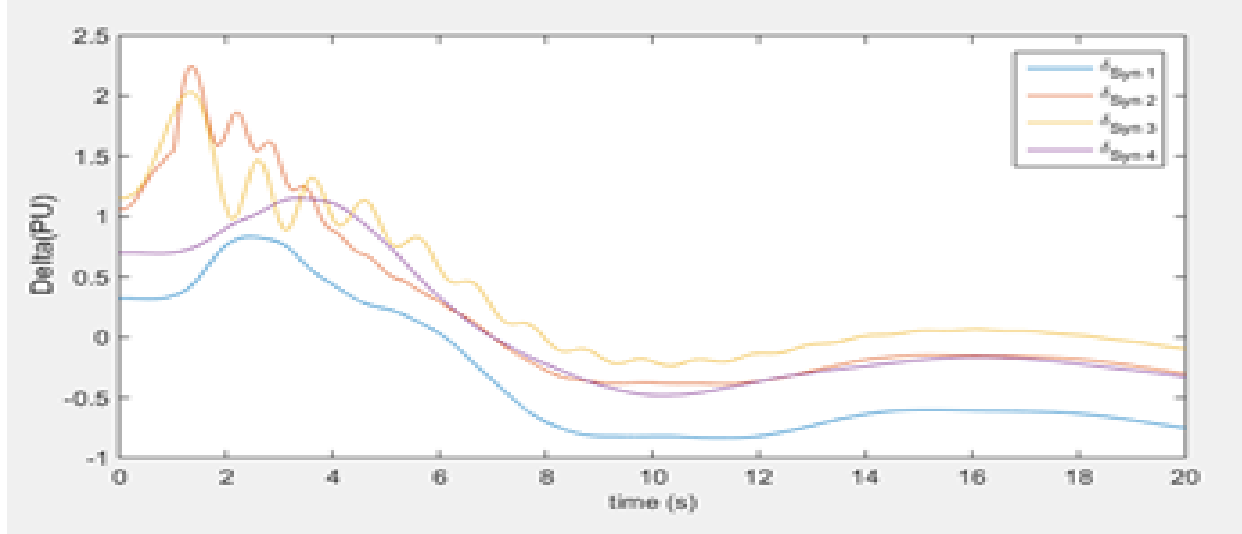

Figure 13 Represent delta against Time for All Generators When the Fault Occurs At Bus No.3 With AVR, TG and PSS Control are used 


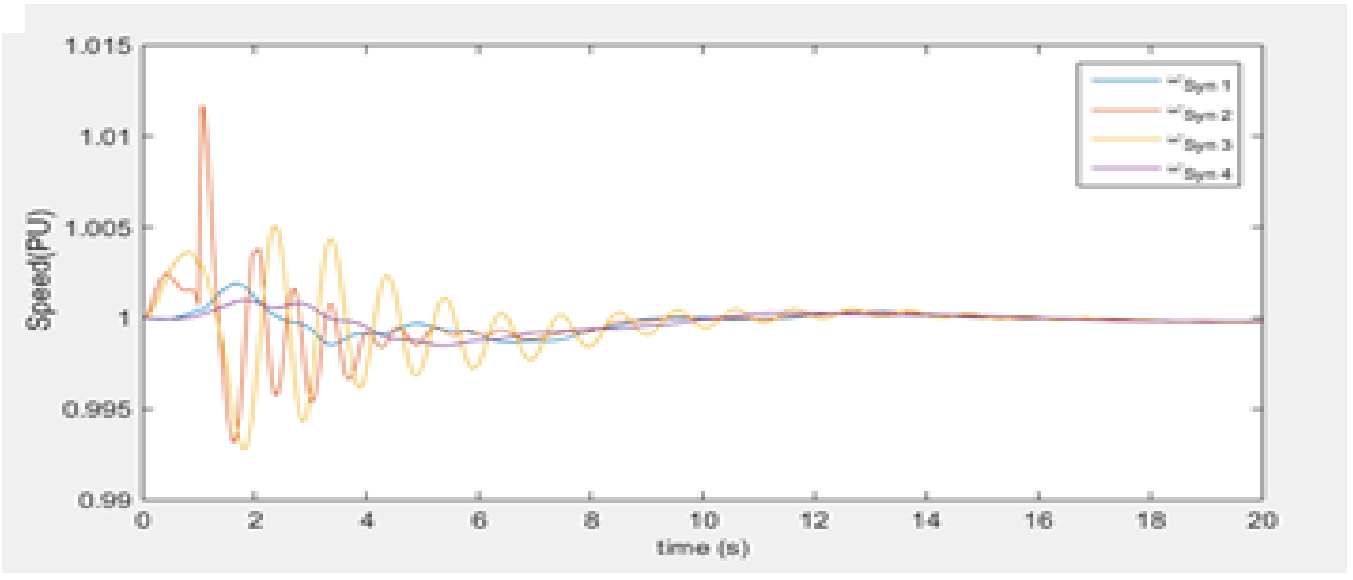

Figure 14 Represent speed against Time for All Generators When the Fault Occurs At Bus No.3 With AVR, TG and PSS Control are used

\subsection{Case No. 2: A 3-phase short circuit at the bus No. 7.}

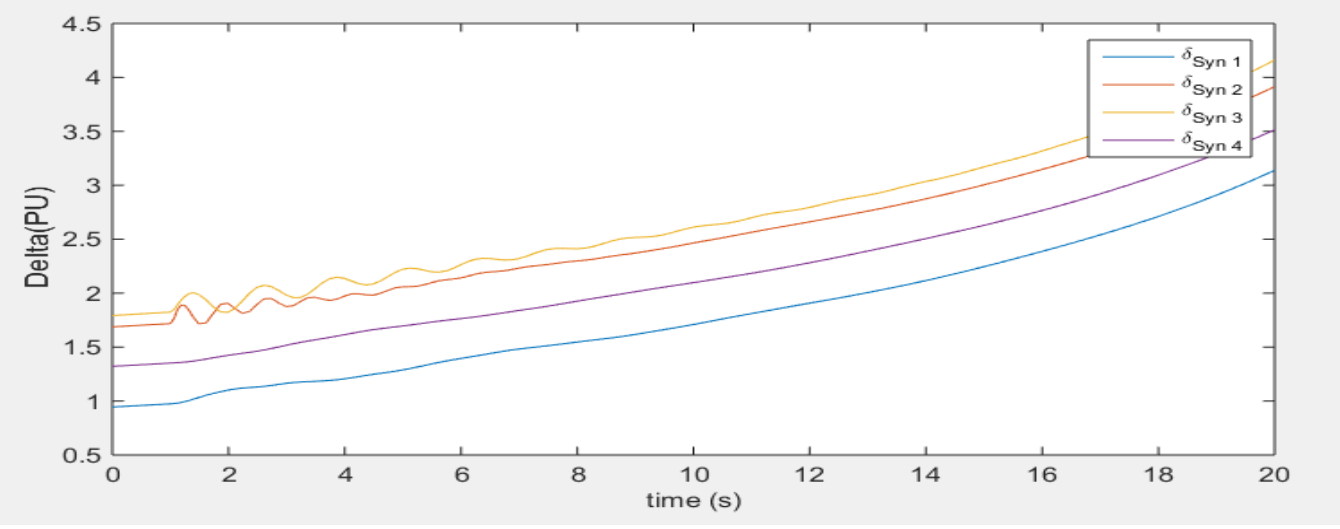

Figure 15 Represent delta against Time for All Generators When the Fault Occurs At Bus No.7 Without Control

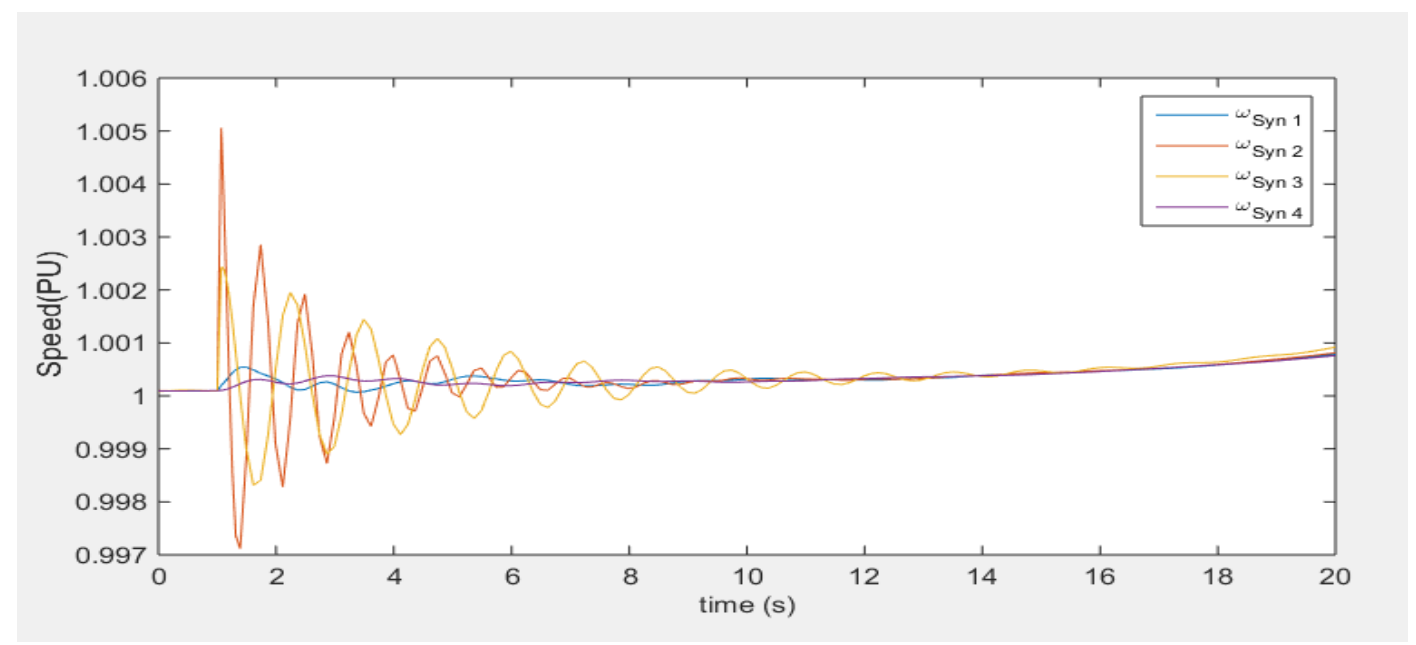

Figure 16 Represent speed against Time for All Generators When the Fault Occurs At Bus No.7 Without Control

In this case, the fault that lasted for 0.066 seconds results instability for generator No.1 and generator No. 2 while generator No.3 is still stable. AVR type 1, TG type 1 and PSS type 
1were used for re-adjusting the generators and the following curves indicates Delta against time and speed against time after using of the control devices.

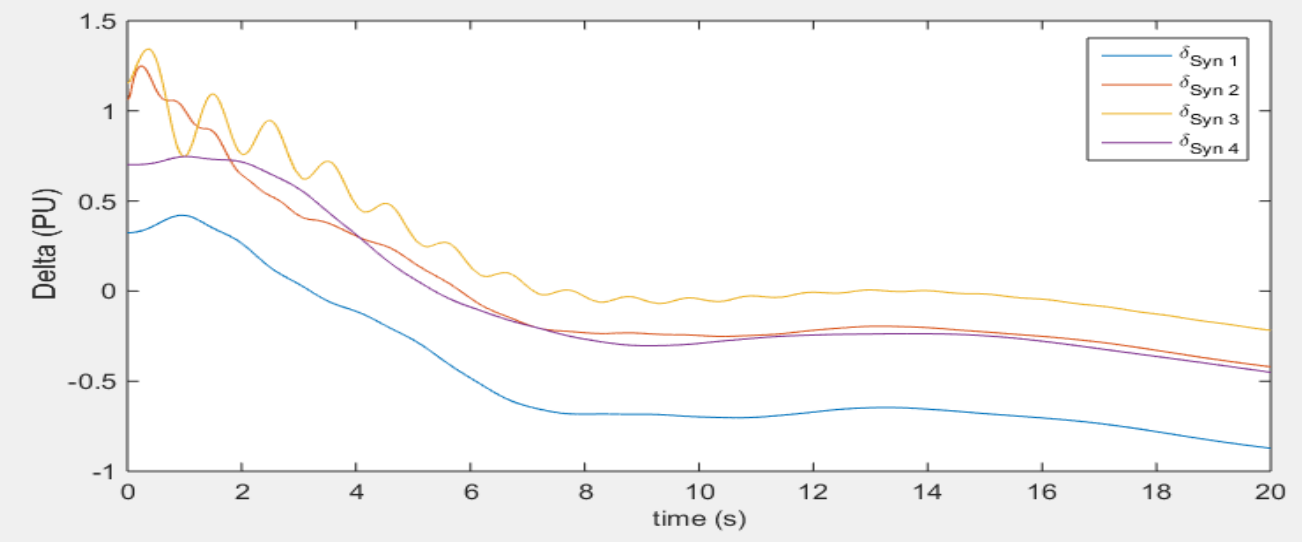

Figure 17 Represent delta against Time for All Generators When the Fault Occurs At Bus No.7 With AVR, TG and PSS Control

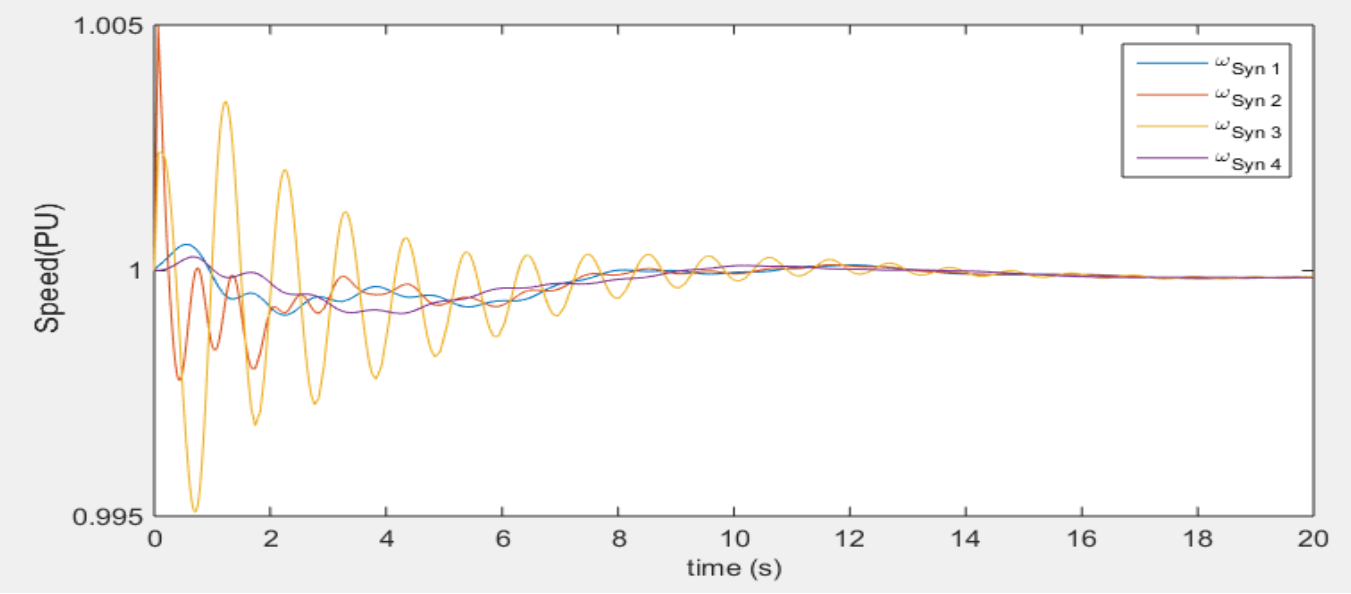

Figure 18 Represent speed against Time For All Generators When The Fault Occurs At Bus No.7 With AVR, TG and PSS Control

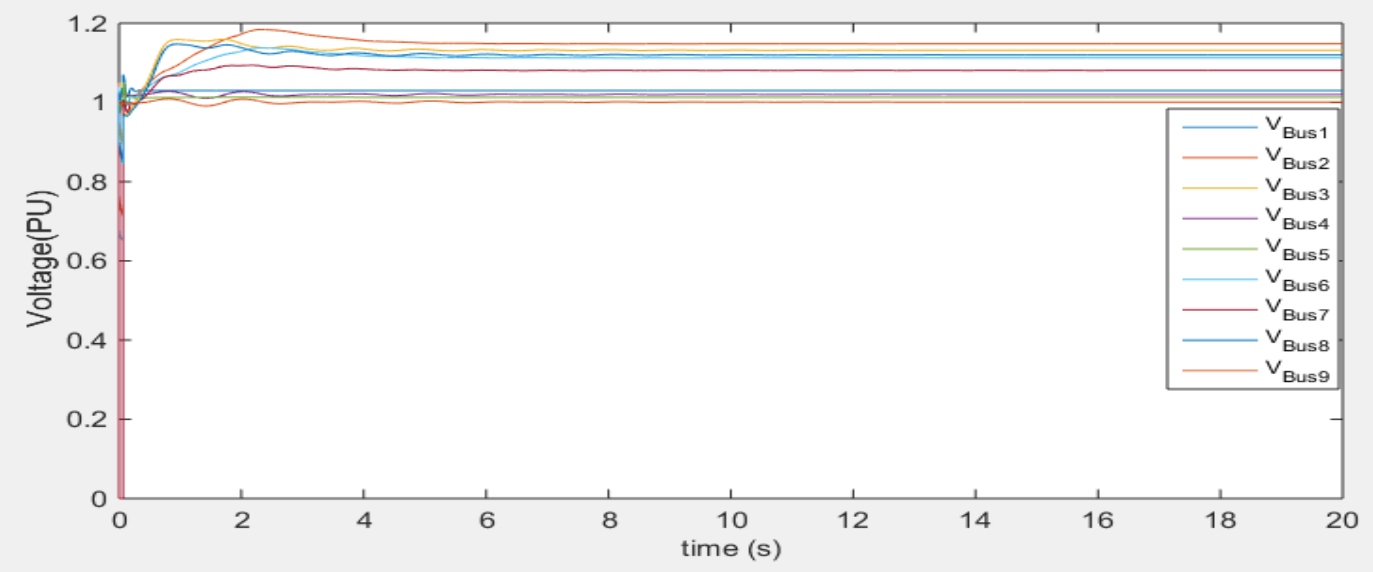

Figure 19. Represent Voltage against Time For All Generators When The Fault OccursAt Bus No.7 With AVR, TG and PSS Control 


\section{CONCLUSIONS}

- The method used in re-adjusting the control devices is a new and suitable for readjusting control devices.

- Both TG \& AVR had proven effectiveness in readjusting unstable generators.

- P.S.S had proven its effectiveness in damping the oscillations that occurs in stable and unstable generators after stability.

- The network of 9 bus and four generators had given positive and excellent results.

- This method had succeeded in re-adjusting the control equipment for instable generator in standard time.

- Voltage profile after readjusting machines at synchronism is accepted.

\section{REFERENCES}

[1] Hassan, Lokman H., M. Moghavvemi, and Haider AF Mohamed. "Power system stabilization based on artificial intelligent techniques; A review." Technical Postgraduates (TECHPOS)2009 International Conference for. IEEE, 2009.

[2] VIJAY VITTAL, Harpole professor, department of electrical and computer engineering LOWA STATE UNIVERSITY - Transient stability and control of large scale power systems, September 4, 2003.

[3] L. Hari, M. L. Kothari, and J. Nanda, -Optimum selection of speed regulation parameters for automatic generation control in discrete mode considering generation rate constraints, Proc. Inst. Elect. Eng. C, vol. 138, no. 5, pp. 401-406, Sep. 1991.

[4] P. W. Sauer and M. A. Pai, Power System Dynamics and Stability. Upper Saddle River, New Jersey: Prentice Hall, 1998.

[5] M. Ili'c and J. Zaborszky, Dynamic and Control of Large Electric Power Sys- tems. New York: Wiley-Interscience Publication, 2000.

[6] Mostafa, Hossam E., et al. "Design and allocation of power system stabilizers using the particle swarm optimization technique for an interconnected power system."International Journal of Electrical Power \& Energy Systems 34.1 (2012): 57-65.

[7] MATLAB/Simulink-based transient stability analysis of a Multimachine Power System, by Ramnarayan Patel, T. S. Bhatti, D. P. Kothari, International Journal of Electrical Engineering Education ISSN: 0020-7209 Volume 39 Issue 4, October 2002, pp 320-336.

[8] W. Xu and Y. Mansour, "Voltage Stability Analysis Using Generic Dynamic Load Models," IEEE Transactions on Power Systems, vol. 9, no. 1, Feb. 1994.

[9] István Erlich, "Analysis and Simulation of Dynamic Behavior of Power System", Postdoctoral lecture qualification, Dept. of electrical engineering, Dresden University, Germany, 1995.

[10] Simon P. Teeuwsen, Istvan Erlich and Mohamed A. El-Sharkawi, "Genetic Algorithm and Decision Tree-Based Oscillatory Stability Assessment", IEEE Trans. on Power Systems, Vol. 21, No. 2, pp. 746-753, May 2006.

[11] RAMNARAYAN PATEL, T. S. BHATTI and D. P. KOTHARI Centre for Energy Studies, Indian Institute of Technology, Hauz Khas, New Delhi, India" 
MATLAB/Simulink-based transient stability analysis of a multimachine power system" September 1,2003.

[12] J. Chow, F. F. Wu, and J. Momoh, Applied Mathematics for Restructured Electric Power Systems. Springer-Verlag, 2005, reference in Chapter 8, Instability Monitoring and Control of Power Systems, by E. H. Abed, M. A. Hassouneh and M. S. Saad, from page 171.

[13] Ameli, A., et al. "Optimal tuning of power system stabilizers in a multi machine system using firefly algorithm." Environment and Electrical Engineering (EEEIC), $201312^{\text {th }}$ International Conference on. IEEE, 2013.

[14] P. Anderson and A. Fouad, Power System Control and Stability. New York: Wiley-IEEE Press, 2002.

[15] Stativa, Andrei, Mihai Gavrilas, and Vasile Stahie. "Optimal tuning and placement of power system stabilizer using particle swarm optimization algorithm." Electrical and Power Engineering (EPE), 2012 International Conference and Exposition on. IEEE,2012.Dddd.

[16] Safari, Amin. "A PSO Procedure for a Coordinated Tuning of Power System Stabilizers for Multiple Operating Conditions." Journal of applied research and technology 11.5 (2013):665-673. 